\title{
Comparative Environmental Sustainability Assessment of Bio-Based Fibre Reinforcement Materials for Wind Turbine Blades
}

\author{
Corona, Andrea; Markussen, Christen Malte; Birkved, Morten; Madsen, Bo
}

Published in:

Wind Engineering

Publication date:

2015

Document Version

Publisher's PDF, also known as Version of record

Link back to DTU Orbit

Citation (APA):

Corona, A., Markussen, C. M., Birkved, M., \& Madsen, B. (2015). Comparative Environmental Sustainability Assessment of Bio-Based Fibre Reinforcement Materials for Wind Turbine Blades. Wind Engineering, 39(1), $53-64$.

\section{General rights}

Copyright and moral rights for the publications made accessible in the public portal are retained by the authors and/or other copyright owners and it is a condition of accessing publications that users recognise and abide by the legal requirements associated with these rights.

- Users may download and print one copy of any publication from the public portal for the purpose of private study or research.

- You may not further distribute the material or use it for any profit-making activity or commercial gain

- You may freely distribute the URL identifying the publication in the public portal 


\title{
Comparative Environmental Sustainability Assessment of Bio-Based Fibre Reinforcement Materials for Wind Turbine Blades
}

\author{
A. Corona ${ }^{2}$, C.M. Markussen', M. Birkved ${ }^{2}$ and B. Madsen' \\ 'Department of Wind Energy, Section of Composites and Materials Mechanics, \\ Technical University of Denmark, Risø Campus, Frederiksborgvej 399, \\ DK-4000 Roskilde, Denmark. \\ ${ }^{2}$ Department of Management Engineering, Quantitative Sustainability Assessment, \\ Technical University of Denmark, Lyngby Campus, Anker Engelundsvej I, \\ DK-2800 Kgs. Lyngby, Denmark
}

Received 06/0I/2013; Revised 0I/09/2013; Accepted 03/09/2014

\begin{abstract}
Over the recent decades biomaterials have been marketed successfully supported by the common perception that biomaterials and environmental sustainability de facto represents two sides of the same coin. The development of sustainable composite materials for wind turbine blades for small-scale wind turbines have therefore partially been focused on substitution of conventional fibre materials with bio-fibres assuming that this substitution was in the better for the environment and human health. The major question is if this material substitution, taking into account a multitude of environmental impact categories, not only climate change, actually is supporting sustainable development or if the development of sustainable composite materials is more complex and perhaps even contra-intuitive due to complex trade-offs. Based on a case study 4 different types of fibres and fibre mixtures (flax, carbon, glass and flax/carbon, flax/glass mixed fibres) are compared in terms of environmental sustainability. Applying one of the most recent life cycle impact assessment methods, we demonstrate that the environmental sustainability of natural fibre based composite materials is similar or even lower, within certain impact categories, than the conventional materials. This observation may seem contra-intuitive (i.e. most people would expect the bio-based to be most sustainable), but is primarily caused by the fact that the resin demand of biobased reinforcement materials is by far larger than that of conventional reinforcement materials. Since the environmental burden of the resin in addition is comparable to that of the fibres (especially in terms human health related impacts), the higher resin demand counterbalances the environmental sustainability improvements, obtained with the application of natural fibres.
\end{abstract}

\section{INTRODUCTION}

The prevalent industrial and scientific interest in bio-based composite materials [1] [2] [3] is mainly related to the technical performance of these new materials; however, despite of their biological origin, the sustainability of the materials needs to be addressed as well. The study at hand addresses the environmental issues by presenting the results of a quantitative comparative sustainability assessment of three prototype small-scale wind turbine rotor blades differing only in type and amount of the composite fibre reinforcement materials. All blades were designed for being applied for the same wind turbine car concept [4] and hence to provide the same service.

Quite a number of life cycle assessments (LCAs) on wind power technology have been published over the last two decades. These assessments mainly focus on the comparison of the environmental burdens of the different life cycle stages of wind turbines, and/or the comparison of complete turbines of various sizes [5]. Many of these studies highlight the fact that the blades are one of the most environmental burdensome parts of a wind turbine. Nonetheless, LCAs focusing on the blades are limited. 
A few studies involving comparative LCAs of various wind turbine blade types have been identified. One of the most recent studies addressing LCA of materials for blades focuses on the use of carbon nanofibres for reinforcement [6] while another study focuses on the use of bamboo also for reinforcement [7]. Both studies demonstrate, although the LCA methodology is not applied rigorously, that the materials used for the blades are having a considerable impact on the blade's environmental performance.

Due to the growing interest in substituting conventional composites, a number of LCAs focusing on bio-based composites in general can be found in the literature. Most of these assessments address solely the energy consumption [8] [9] and/or applies obsolete LCIA methodologies based on e.g. rather simplified characterization methods [10]. In the present study, a recent LCIA methodology is used, allowing for an assessment covering a wide spectrum of impact categories applying state-ofthe-art characterization methods and hence characterization models [11].

In the present study, flax fibres were selected as the bio-based composite reinforcement, and carbon and glass fibres were selected as the conventional composite reinforcements. For all three types of fibres, a bio-based epoxy resin with typical mechanical properties, but sourced from biowaste was selected for the matrix. In a previous study [12], technical documentation was provided for the mechanical properties of the three composite types: flax/epoxy, carbon/epoxy, and hybrid 50/50 flax-carbon/epoxy. Based on this information, finite element models were constructed to dimension prototypes of small-scale wind turbine blades. Manufacturing of the blade prototypes was done using a vacuum infusion technique to ensure high quality and reproducibility corresponding to industrial standards [12].

In preliminary work [13], a comparative LCA of the above mentioned three blade prototypes was carried out, and based on this study it was concluded that more detailed analyses were needed. In addition, it was further recommended to include glass fibres as yet another type of conventional composite reinforcement, in order to identify the relevant environmental trade-offs in the hybrid composite blade product systems. To assess the hybrid blade type scenarios in the present study, and in order to determine the mass of the blades made of different composite materials and meeting the same mechanical function requirements, the material selection methodology developed by Ashby [14] was used. This methodology has been successfully applied before in another comparative LCA study [10].

\section{METHODS}

The product system model was set-up in GaBi 4.4 [15], and built based on readily available commercial unit processes from either the GaBi professional database [16] or the Ecoinvent database [17]. The parameterised model is illustrated in Figure 1. The product system model covers all relevant life cycle stages of the wind turbine blades from extraction of raw materials, such as crude oil for the traditional epoxy resin, to fuels for waste disposal (here incineration with energy recovery) of the blades. The experimental inputs for the model are the materials quantities and the energy consumed during production of the blade prototypes.

All assumptions made relating to the biobased epoxy composition were based on the findings presented in the study by Rusu et al. [18]. The availability of representative unit processes and hence inventory data further had to be taken into consideration, and accurate compromise alternatives had to be applied in order to establish an operational product system model. One such compromise inventory solution relates to the vegetable oil feedstock for the SuperSap 100 biobased epoxy applied for the blades, which is pine oil [19]. No unit processes for pine oil could be located via the inventory data sources available to us, and hence in order to simulate the impacts associated with the exchanges between environment and sub-product system(s) associated with the production of the vegetable oil, a compromise inventory solution had to be applied. The compromise chosen for the specific inventory of the pine oil production is a unit process for (organic) rape seed oil production. Rape seed oil is a frequently applied feedstock for biobased epoxy and is hence considered being an appropriate and realistic feedstock representative for pine oil. Choosing the organic rape seed oil production form further avoids introduction of impacts related to the pesticide application occurring in conventional seed oil production. The applied unit process selection procedure is frequently used in relation to product system modelling, since inventories for many frequently occurring and quite common unit processes have still not been established [20].

Allocation of impacts from the oil used for the production of the biobased epoxy was based on the assumption that pine oil is an unintended by-product of the Kraft process, obtained during pulping of wood. Since the driving product of the pulping process is the wood pulp, it is possible to 


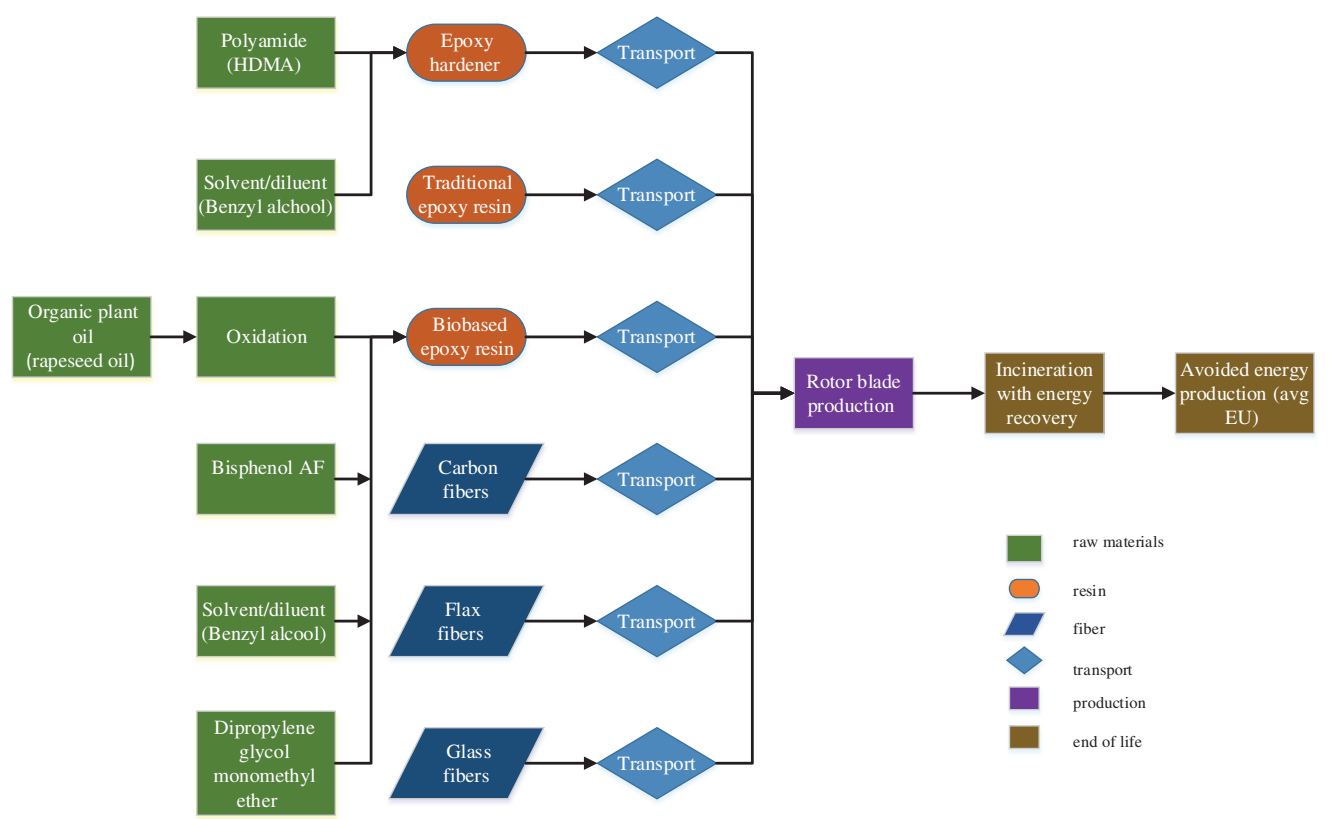

Figure I. Overview of the wind turbine blade product system model, which is capable of modelling the types of composite materials assessed in the present study

assign a zero allocation factor of impacts to the oil (i.e. the oil will be produced whether there is a demand for it or not). In the present study, however, a slightly conservative allocation approach was used, allocating $5 \%$ of the wood pulp production impacts to pine oil, based on the fact that $1000 \mathrm{~kg}$ of pulp produces $20-50 \mathrm{~kg}$ of oil [21]. Furthermore, the concentrations of the individual constituents in the biobased epoxy had to be estimated partly based on [18], [19], [22], in addition to common sense (e.g. that all constituents of a given material have to sum to $100 \%$ ).

In relation to the parameterisation of the product system model, transport means and distances for the materials had to be estimated based on knowledge of the typical transport means used from the material producers to the blade production location. The chosen transport mean here is shiptransport, which in extreme cases (i.e. urgent orders relying on air cargo transport) could give an underestimate of the impact from the transport stage, but it allows for obtaining results not strongly dependent on the transport distance [17]. Ship-transport is due to its cost efficiency considered the most likely transportation mean for all the relevant materials.

All estimation work relating to model construction and model parameterisation reflects the actual conditions as accurately as possible, and hence the uncertainties relating to the estimation work and assumptions are as low as possible. It is important to keep in mind that the uncertainties relating to the estimation work are approximately equally large for all the studied blade type scenarios and originate from the same sub-models. Thus, the overall ratios between the impact potentials of the blade types are therefore considered to have a considerably lower uncertainty than the absolute impact potentials, i.e. many of the uncertainties being the same for all blade types will equal out by the comparison.

In the present comparative LCA, the same functional unit is used for the different blade type scenarios. The functional unit is: "production of one blade that meets the specific requirements for the mechanical performance of a blade". An essential requirement used in the mechanical design of a rotor blade is to allow only a given bending deflection of the blade. Hence all the blades have to meet the same bending stiffness requirement. For some of the studied blade type scenarios (flax composite, carbon composite, and hybrid 50/50 flax/carbon composite), a full mechanical analysis of the blades has been performed in a previous study [12], and prototypes of these blades have been produced. For the remaining studied blade type scenarios (glass composite, and hybrid composites with different fibre mixing ratios), no mechanical analysis has been done, and these blades have not been produced. Hence, in the cases where mechanical analysis data are lacking, there is a need for a methodology to determine the mass of a blade made with different composite materials, and meeting the required bending stiffness.

The methodology chosen to determine the mass of the blades is based on the well-known material selection methodology developed by Ashby [14]. This methodology allows for estimating 
the mass of an object made with variable materials (i.e. also composite materials) while meeting the design requirements (geometry and mechanical performance). In the present study, the blade was assumed comparable to a beam under bending loading conditions. For a beam with a given required bending stiffness, the mass of the beam $(\mathrm{m})$ is given by:

$$
\mathrm{m}=\mathrm{C} * \frac{\rho}{\mathrm{E}^{\frac{1}{2}}}
$$

where $\mathrm{C}$ is a constant dependent on the given geometrical dimensions of the beam, the given loading conditions and the given bending stiffness, $\rho$ is the material density and $\mathrm{E}$ is the Young's modulus. Thus, the Ashby index for a beam under bending loading conditions is $E^{1 / 2} / \rho$. This index needs to be maximized in order to minimize the mass of the beam. The ratio in masses between two beams made from different materials, both having the same required bending stiffness, is given by:

$$
\frac{\mathrm{m}_{1}}{\mathrm{~m}_{2}}=\frac{\rho_{1}}{\mathrm{E}_{1}^{\frac{1}{2}}} * \frac{\mathrm{E}_{2}^{\frac{1}{2}}}{\rho_{2}}
$$

Hence

$$
\mathrm{m}_{1}=\left(\frac{\mathrm{E}_{2}}{\mathrm{E}_{1}}\right)^{\frac{1}{2}} \frac{\rho_{1}}{\rho_{2}} \mathrm{~m}_{2}
$$

Using the known masses of the flax and carbon composite blade type scenarios (i.e. the produced blade prototypes), the unknown masses of the other studied blade type scenarios were determined by the equation. The material properties ( $\rho$ and $E$ ) for the flax and carbon composites were measured in the study by Bottoli and Pignatti [12], while properties for the glass composite were obtained from the literature [23]. The results are presented in Table 1. In order to evaluate the accuracy of the applied methodology, the known blade masses for the flax and carbon composite blade type scenarios were also calculated. The relative small difference between the known and calculated masses (454 vs. $474 \mathrm{~g}$ for the flax composite blade, and $246 \mathrm{vs.} 235 \mathrm{~g}$ for the carbon composite blade) is validating the applied methodology.

The same Ashby methodology was applied to calculate the unknown blade masses for the hybrid composite blade type scenarios. For these composites, a macromechanical model was chosen to analyse the hybrid situation [24]. This model allows calculating the composite content, density and Young's modulus of the hybrid composites as a function of the hybrid fibre weight mixing ratio $(\beta)$ :

$$
\beta=\frac{m_{f 1}}{m_{f 1}+m_{f 2}}
$$

where $m_{f 1}$ and $m_{f 2}$ are the masses of the two fibre types in the hybrid composites. $\beta$ has values in the range $0-1$, where $\beta=0$ and $\beta=1$ designate the situations of the two non-hybrid composites containing only one fibre type.

Table 2 presents the determined blade masses for the hybrid flax/carbon and flax/glass composite blade type scenarios.

Table I. Determined blade masses for the studied blade type scenarios, simple non-hybrid composites. Input data ( $\rho$ and E) are from [12] and [23]. The calculated masses are obtained using the carbon composite blade as reference (c) or the flax composite blade (f)

\begin{tabular}{lccccc}
\hline Blade type & $\begin{array}{c}\text { Fibre content } \\
\text { [\% weight] }\end{array}$ & $\begin{array}{c}\text { Density, } \\
\boldsymbol{\rho} \\
\text { scenarios }\end{array}$ & $\begin{array}{c}\text { Young's } \\
\text { modulus, } \\
\text { E [GPa] }\end{array}$ & $\begin{array}{c}\text { Blade mass, } \\
\text { real prototype } \\
\text { [g] }\end{array}$ & $\begin{array}{c}\text { Blade mass, } \\
\text { calculated } \\
\text { [g] }\end{array}$ \\
\hline Flax composite & 42 & 1.26 & 20 & 454 & $474(\mathrm{c})$ \\
Carbon composite & 63 & 1.49 & 104 & 246 & 235 (f) \\
Glass composite & 72 & 1.88 & 38 & & 492 (f) 513 (c) \\
\hline
\end{tabular}


Table 2. Determined blade masses for the studied blade type scenarios, hybrid composites

\begin{tabular}{|c|c|c|c|c|c|c|}
\hline $\begin{array}{l}\text { Blade type } \\
\text { scenarios }\end{array}$ & $\begin{array}{c}\beta \\
{[-]}\end{array}$ & $\begin{array}{c}\text { Fibre composite } \\
\text { content } \\
{\left[\begin{array}{ll}\% & \text { weight }\end{array}\right]}\end{array}$ & $\begin{array}{c}\text { Density, } \\
\rho\left[\mathrm{g} / \mathrm{cm}^{3}\right]\end{array}$ & $\begin{array}{c}\text { Young's } \\
\text { modulus, } \\
\text { E [GPa] }\end{array}$ & $\begin{array}{c}\text { Blade mass, } \\
\text { real prototype } \\
{[\mathrm{g}]}\end{array}$ & $\begin{array}{c}\text { Blade mass, } \\
\text { calculated } \\
{[\mathrm{g}]}\end{array}$ \\
\hline \multirow{6}{*}{$\begin{array}{l}\text { Hybrid } \\
\text { flax/carbon } \\
\text { composites }\end{array}$} & 0.0 & $0 \%$ & 1.49 & 104 & 246 & 235 \\
\hline & 0.1 & $14 \%$ & 1.45 & 90 & & 252 \\
\hline & 0.2 & $27 \%$ & 1.41 & 78 & & 264 \\
\hline & 0.5 & $60 \%$ & 1.34 & 50 & 309 & 312 \\
\hline & 0.8 & $86 \%$ & 1.28 & 30 & & 386 \\
\hline & 1.0 & $100 \%$ & 1.26 & 20 & 454 & 476 \\
\hline \multirow{6}{*}{$\begin{array}{l}\text { Hybrid } \\
\text { flax/glass } \\
\text { composites }\end{array}$} & 0.0 & $0 \%$ & 1.88 & 38 & & 492 \\
\hline & 0.1 & $16 \%$ & 1.74 & 34 & & 487 \\
\hline & 0.2 & $30 \%$ & 1.64 & 31 & & 479 \\
\hline & 0.5 & $63 \%$ & 1.43 & 25 & & 466 \\
\hline & 0.8 & $87 \%$ & 1.31 & 22 & & 460 \\
\hline & 1.0 & $100 \%$ & 1.26 & 20 & 454 & 476 \\
\hline
\end{tabular}

For the assessment of the environmental impacts induced by the different blade type scenarios, the ReCiPe Life Cycle Impacts Assessment (LCIA) methodology was applied. ReCiPe is considered by the LCA community to be one of the most recent and complete LCIA methodologies [13]. In the present study, the hierarchical assessment perspective is used, both in terms of characterization and normalization factor. This perspective represents a set of choices on issues like time perspective or expectations that proper management or future technology development can avoid future damage. Between the three perspective available in the ReCiPe methodology it is the most used and considered the default model. [11].

The ReCiPe methodology allows for assessment both on midpoint and on endpoint level. In the present study, the endpoint indicator results are shown along with the respective contributions from the individual midpoint impact categories.

\section{RESULTS AND DISCUSSION}

Figure 2 presents the summarized LCIA results at endpoint level and at the single score level for the three non-hybrid blade type scenarios (flax composite, carbon composite, and glass composite).

The endpoint results in Figure 2 indicate that the carbon fibre composite blade has the worst impact burden performance in all three endpoint categories. This is most pronounced in terms of ecosystem damage as well as for the resource depletion, while for human health damage, the three blades show quite uniform performances. Glass and flax composite blades perform almost equally well, however the glass composite blade has a somewhat lower contribution to the human health endpoint category. In terms of burden contributions to specific endpoint categories, in general for all three non-hybrid blade type scenarios, the most important midpoint impact categories contributions are:

- Climate change, both in terms of contributions to ecosystem damage and human health.

- Human toxicity, in terms of contributions to human health which is mainly related to the resin production.

- Fossil fuel depletion in terms of contributions to resource depletion.

The single score graph in Figure 2 reveals that the carbon fibre composite blade overall has the largest environmental burden. Glass and flax composite blades perform almost equally well, with the flax composite having a slightly better performance than the glass composite. In Figure 3 the contributions from each life cycle stage to the total single score profiles for the nonhybrid blade type scenarios are presented. In order to illustrate how the different life cycle stages affect the overall impact of the blades, the results are presented as a percentage of the individual single scores. 


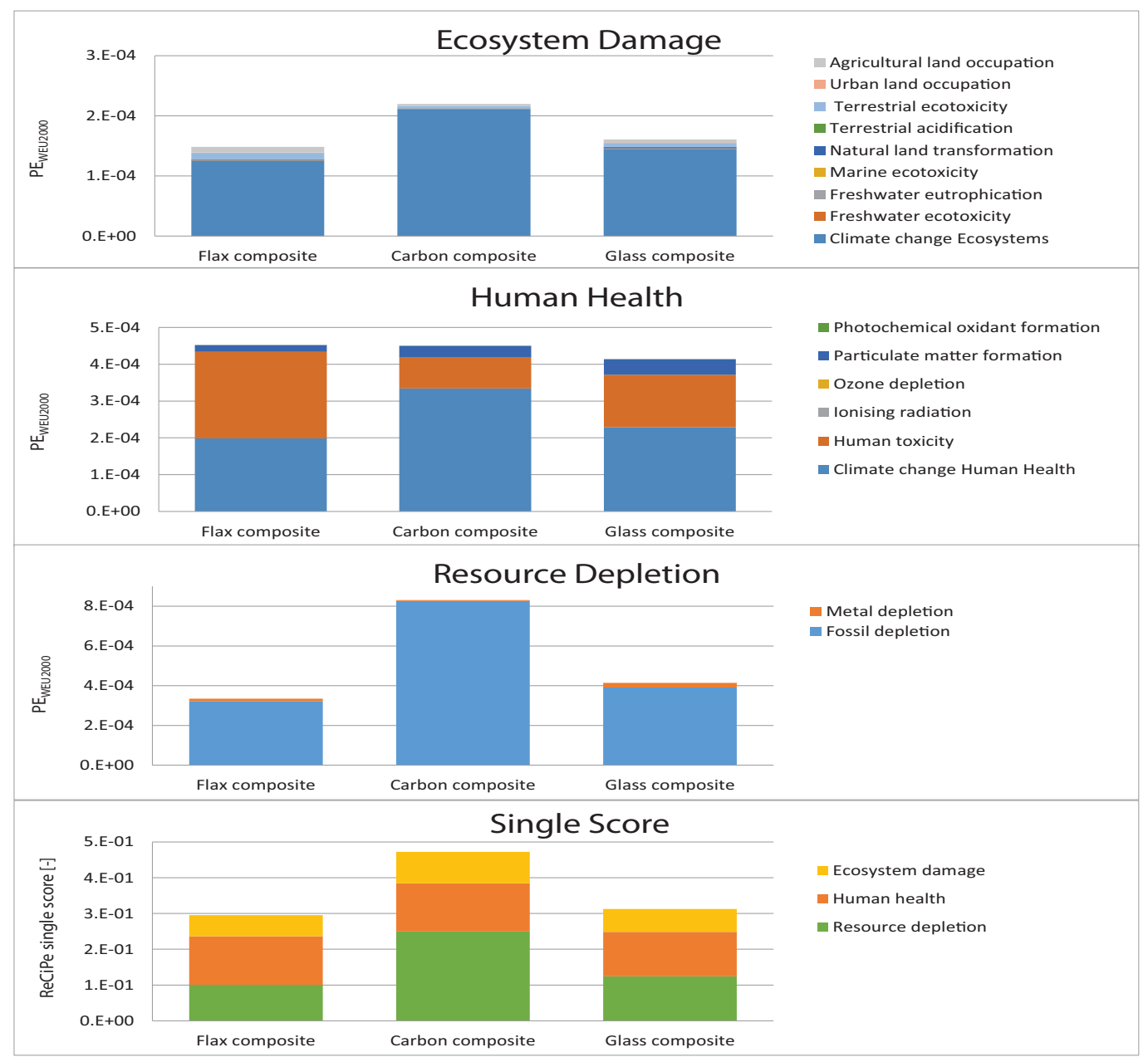

Figure 2. ReCiPe endpoint scores for the three non-hybrid blade type scenarios at endpoint level and at single score level. The first three graphs show the contribution from the different midpoint impact categories to each endpoint category, while the last graph shows the contribution from the different endpoint categories to the single score (all data were obtained in accordance with the hierarchist perspective)

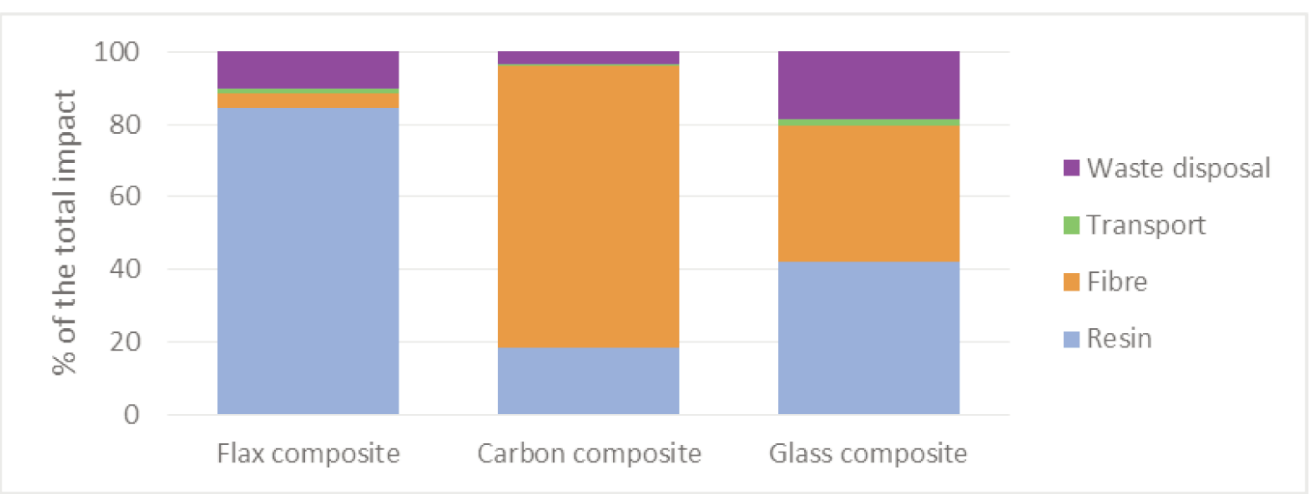

Figure 3. Life cycle stage specific ReCiPe single score contributions for the three non-hybrid blade type scenarios. Each graph shows the contribution from the individual life cycle stages to the single score of the blade (all data were obtained according to the hierarchist perspective)

As can be observed in Figure 3, the contributions from the individual life cycle stages are noticeably different for the three blade type scenarios:

- In the carbon composite blade type scenario, the dominant impact is related to the fibre production, because carbon fibre production is a highly energy demanding process and the 
energy comes from fossil sources. This dominance is further emphasised by the small amount of resin needed for the infusion of the carbon composite blade (in comparison to the flax composite blade, see Table 1), i.e. this causes a relative larger burden contribution from the fibres.

- In the flax composite blade type scenario, the dominant impact is related to the resin production. This is caused by the large amount of resin needed for the infusion of the flax composite blade (see Table 1). In addition, flax fibre production has a low impact contribution, since flax fibres are of biological origin and hence do not require large amounts of energy for in relation to carbon or glass fibre production.

- In the glass composite blade type scenario, there are almost equal contributions from the fibre production and the resin production. Glass fibre production is a highly optimized process, hence the impact from energy consumption for fibre production is low compared to the one observed for carbon fibres. The impact contribution of the fibre production is, however, still comparable to the impact observed for the resin production. Contrary to the other two blade type scenarios, the glass composite blade has a considerable impact contribution from waste disposal. Since the glass composite blade has the highest mass (see Table 1), this results in a demand for more waste transportation and waste treatment. Furthermore, since only the resin part can be incinerated, waste disposal of the glass composite blade results in lower energy recovery (on a weight basis) upon incineration compared to e.g. the flax composite blade.

For the hybrid blade type scenarios, the environmental burden obviously varies according to the hybrid fibre mixing ratio $(\beta)$. Figure 4 shows the endpoint score contributions for the hybrid flax/carbon composite blades with increasing $\beta$ values, i.e. with increasing amount of flax fibres. The analogue situation with the hybrid flax/glass composite blades is shown in Figure 5.

Regarding the hybrid composite blade type scenarios presented in Figures 4 and 5, a clear trend can be observed; with increasing $\beta$ values (i.e. increasing amount of flax fibres), the endpoint scores are reduced for the ecosystem damage and the resource depletion. This is the logical and expected outcome from increasing the amount of flax fibres that do not consume considerable amounts of

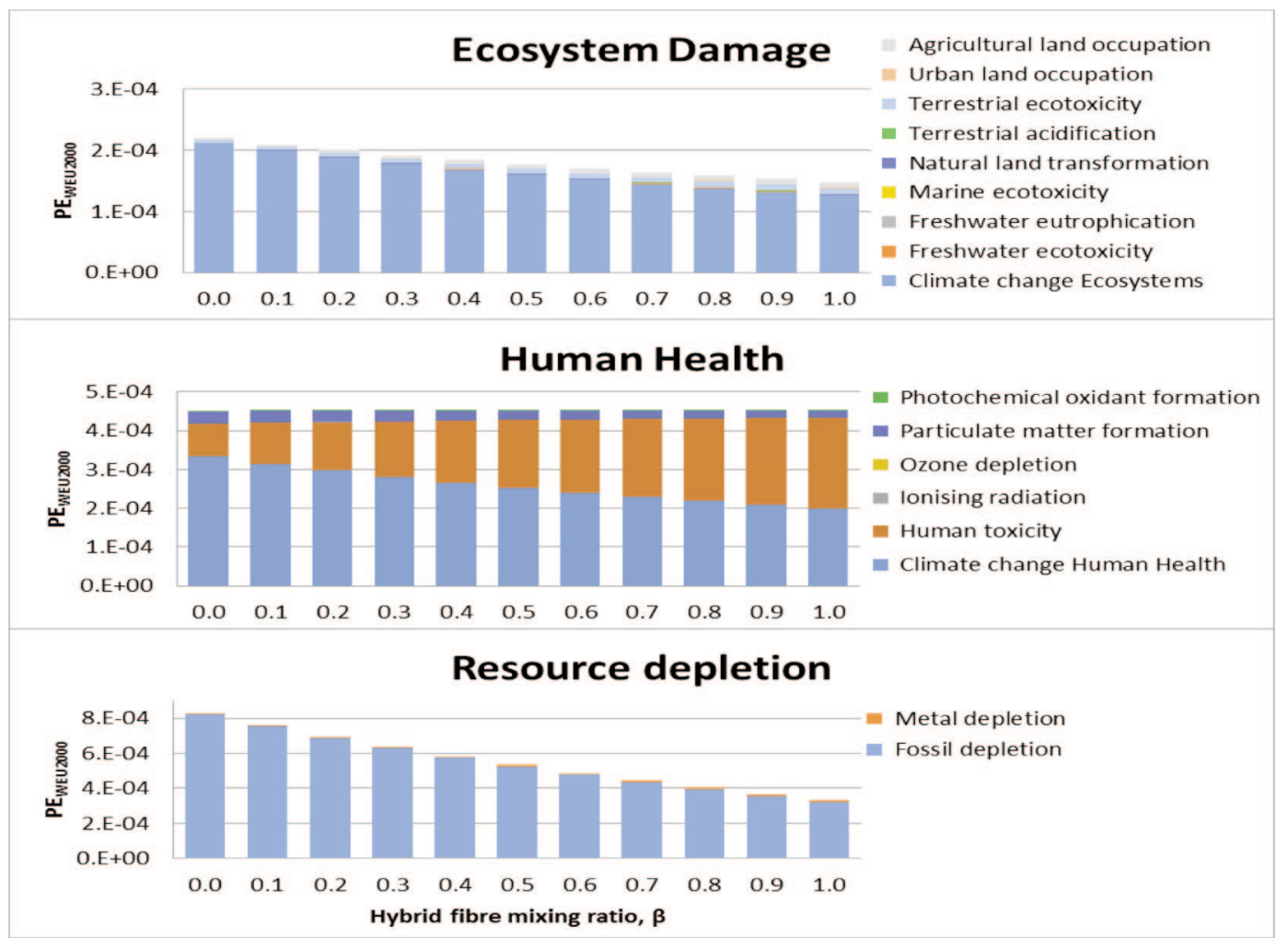

Figure 4. ReCiPe endpoint scores for the hybrid flax/carbon composite blades with increasing hybrid fibre mixing ratios ( $\beta$ ), i.e. with increasing amount of flax fibres. The graphs show the contribution from the different midpoint impact categories to each endpoint category (all data were obtained in accordance with the hierarchist perspective) 


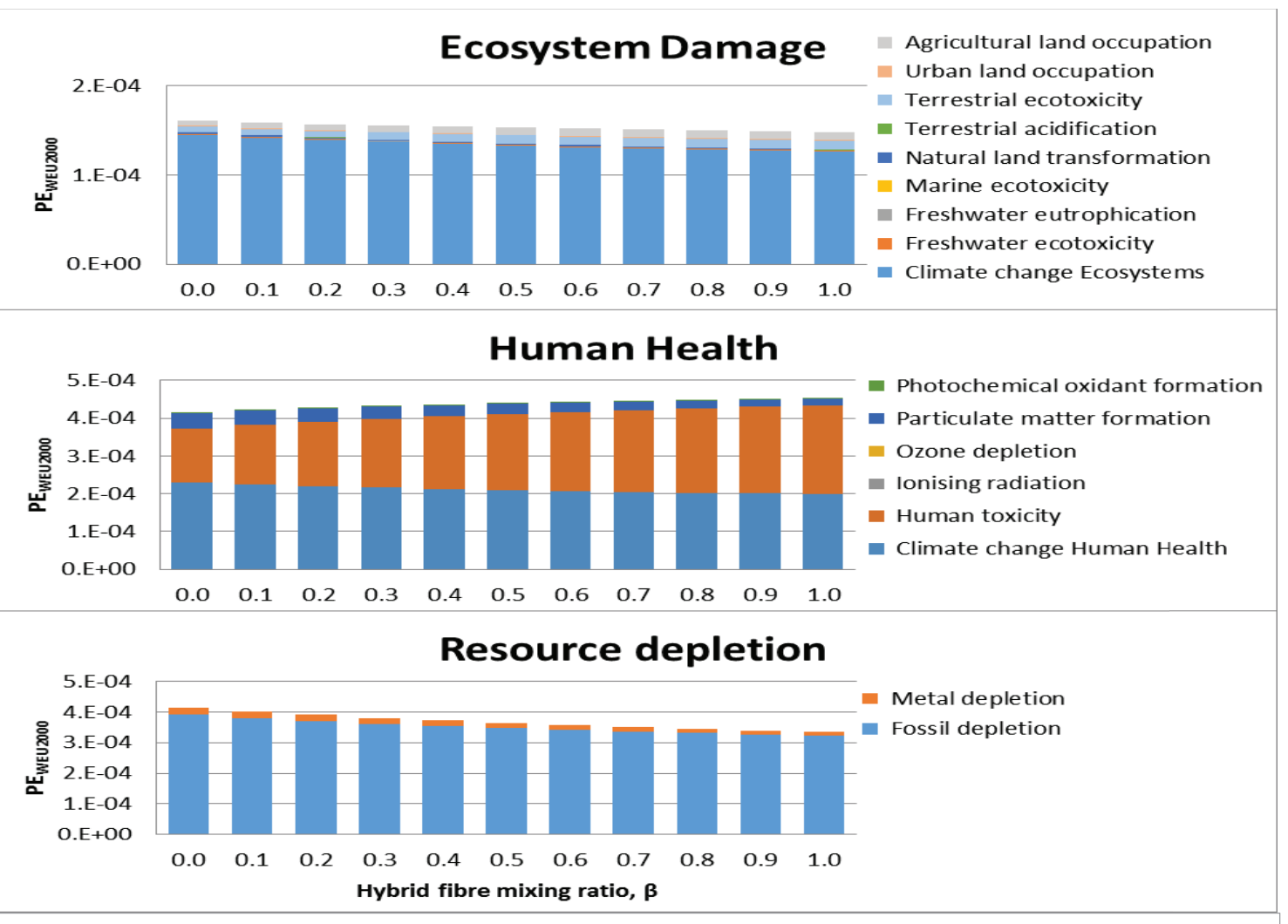

Figure 5. ReCiPe endpoint scores for the hybrid flax/glass composite blades with increasing hybrid fibre mixing ratios $(\beta)$, i.e. with increasing amount of flax fibres. The graphs show the contribution from the different midpoint impact categories to each endpoint category (all data were obtained in accordance with the hierarchist perspective)

energy and only consume few fossil resources during their production. The human health endpoint category on the other hand reveals a different trend. When the amount of flax fibres is increased, the impact contribution to this endpoint category is slightly increased. By focusing on the climate change midpoint contribution to the human health endpoint category, it is observed that the endpoint score contribution from this midpoint category decreases when the amount of flax fibres is increased. However, this positive climate change effect does not counterbalance the increase in the endpoint score contribution from the human toxicity midpoint category, which is due to the larger amount of resin needed for the infusion of the flax fibre composite, compared to the two conventional fibre composites (see Table 1).

Comparing the non-hybrid and hybrid blade burden profiles in figure 6 reveals that of the hybrid regardless of endpoint category has worse or close to equal environmental outcomes as the nonhybrid blade. The hybrid blade is consistently performing equal or better than the carbon composite solution and consistently worse or equal to flax and glass composites.

In the present study, it has not been possible to quantify the uncertainties related to the inventory, characterization and damage modelling. To our knowledge it is not possible to quantify the uncertainties related to the presented endpoint scores. One possibility would be to apply rather crude inventory uncertainty estimation techniques such as e.g. the pedigree matrix [25]. However, the uncertainty related with these crude uncertainty estimates (i.e. the uncertainty of the uncertainty) is most likely of considerable proportions due to the rudimentary nature of these techniques. Assessments on damage level, as the one presented here, are quantified based on multiple modelling steps: characterization modelling, damage modelling and in some case inventory modelling. Since modelling of natural systems de facto has considerable uncertainties, it does not make sense only to quantify and include the inventory related uncertainties, when it is likely that the characterization modelling and damage modelling related uncertainties could be even larger and overshadow the 


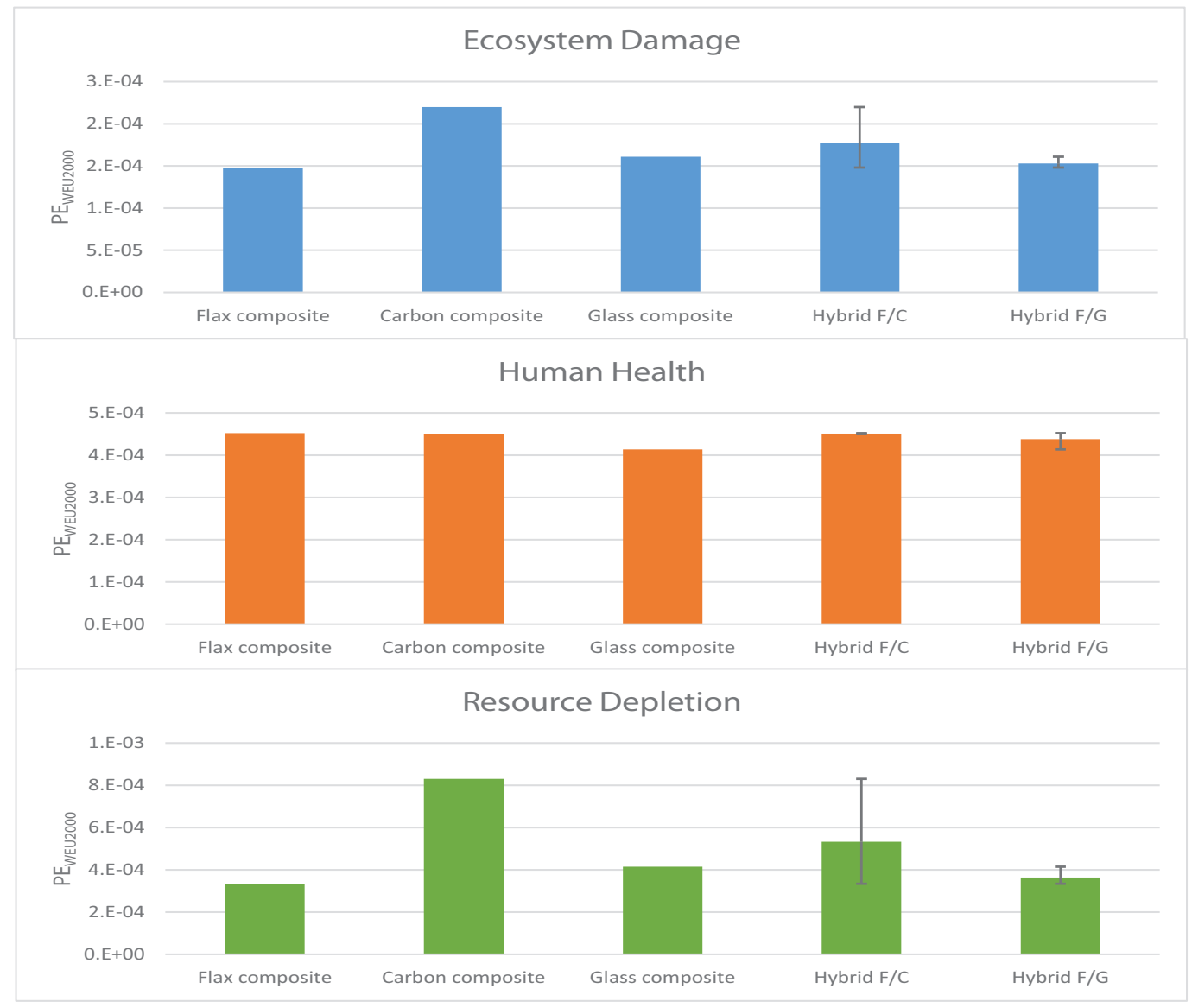

Figure 6. ReCiPe endpoint scores for the three non-hybrid blade type scenarios and the two hybrid scenarios with their composition range ( $\mathrm{F} / \mathrm{C} \mathrm{Flax} /$ Carbon and $\mathrm{F} / \mathrm{G} \mathrm{Flax} / \mathrm{Glass}$ ) at endpoint category level. (All data were obtained in accordance with the hierarchist perspective). The endpoint scores for the hybrid are those obtained for hybrid fibre mixing ratios $(\beta)$ of 0,5$)$. The error bars on the hybrid blade columns quantifies the $\beta$ dependent variation of the impact score from in the range $0 \leq \beta \leq 1$

inventory uncertainty. Only providing inventory rooted uncertainties could hence provide a false sense of certainty, i.e. giving the false impression that uncertainty is sufficiently addressed.

The uncertainties of a LCIA, such as the one presented here, are typically of considerable magnitude [26]. The inventory related uncertainties of the present assessment are most likely in accordance with [25] yielding coefficients of variation no less than 35-50\%. This means that despite that the endpoint scores presented in e.g. Figure 2 appearing to be (slightly) different for the considered blade type scenarios, it is not possible to tell whether or not these actually are significantly different. It would be possible only after having quantified the exact confidence intervals of the LCIA results including the aggregated inventory, characterization modelling and damage modelling uncertainties. Thus, when interpreting the results presented in this study it is important to keep in mind the missing uncertainty assessment, which however only can be provided once exact uncertainties are provided for all inventory data, including the data which had to be estimated, as well as the characterization and damage modelling steps.

\section{CONCLUSIONS}

This paper considered the life cycle assessment of a range of materials that could be used for small wind turbine blade production. From the results of the study, the application of natural fibres such as flax fibres as reinforcement of bio-plastics, at first glance seems like an idea that intuitively should offer a positive effect in terms of environmental sustainability performance of composites. The fact that bio-composites based on natural fibres, with present technology, 
demand considerable (in our case almost 3 times) more epoxy, however counterbalances the environmental impacts avoided by the bio-fibres of the bio-composites by application of e.g. flax fibres instead of glass fibres. Since bio-epoxies despite being based on a natural oil feedstock, are by no means environmental neutral (i.e. bio-epoxies have environmental impact profiles of same magnitude as conventional epoxies), the increased epoxy demand of natural fibres based biocomposites, results in a negative trade-off between impacts caused by fibres and impacts caused by bio-epoxy. This impact trade-off is however mainly driven by the human health impacts related to the bio-epoxy use.

Regarding the use of the bio-based epoxy, our study demonstrates a positive effect in the mitigation of the impact caused by the resin but these impacts are still considerable (results relating to this study are presented in Figure 6 in the supporting information).

Another important aspect originates from the use of the Ashby methodology. In this case the blades are assumed to behave like a beam. In other situations (e.g. panel in bending) the Ashby's index is lower resulting in a better performance for the flax composite compared to that of the glass composite. This situation was analysed in a previous study [8]. In our case the flax composite product will be lighter than the same product produced relying on glass fibres as reinforcement. The differences in the impacts induced by the blade alternatives analysed in here, are in most cases so small that the differences are statistically insignificant (see Figure 6). Due to the small differences more precise inventory data are needed, especially on the bio-resin constituents, in order to come up with a statistical justifiable conclusion on which blade alternative actually has the optimum environmental profile.

\section{REFERENCES}

[1] J. Mussig, Industrial Applications of Natural Fibres - Structure, Properties and Technical Applications. United Kingdom: Wiley, 2010.

[2] K. Pickering, Properties and performance of natural fibre composites. Cambridge, England: Woodhead Publishing Limited, 2008.

[3] A. Mohanty, M. Misra, and T. Lawrence, Natural Fibres, Biopolymers and Biocomposites. Florida: CRC Press, 2005.

[4] M. Gaunaa, S. _ye, and R. Mikkelsen, Theory and Design of Flow Driven Vehicles Using Rotors for Energy Conversion. Lyngby, DK: To be published, 2009.

[5] Davidsson, S., Höök, M., \& Wall, G. (2012). A review of life cycle assessments on wind energy systems. The International Journal of Life Cycle Assessment, 17 (6), 729-742. doi:10.1007/s11367-012-0397-8.

[6] L.-A. Mergula, G.W. Lowrie, V. Khana, B.R. Bakshi. Comparative life cycle assessment: Reinforcing wind turbine blades with carbon nanofibers. 2010 IEEE International Symposium on Sustainable Systems and Technology (ISSST).

[7] J. Xu, Y. Qin, Y. Zhang. Bamboo as a potential material used for windmill turbine blades. Master thesis from Roskilde University, Denmark, 2009.

[8] Corbière-Nicollier, B., Gfeller Laban, L., Lundquist, Y. Leterrier, J., Manson, A.J., Jolliet, O. (2001): Life cycle assessment of biofibres replacing glass fibres as reinforcement in plastics. Resources Conservation and Recycling 33, 267-287.

[9] S. Pandita, X. Yuan, M. Manan, C. Lau, A. Subramanian, J. Wey. Evaluation of Jute/glass hybrid composite sandwich: Water resistance, impact properties and life cycle assessment. Journal of reinforced plastic and composite 2014 33:14.

[10] A. Le Duigou, J.M. Deux, P. Davies, C. Baley. PLLA/Flax Mat/Balsa Bio-sandwich Environmental impact and simplified Life Cycle analysis Applied Composite Materials, 2012 - Springer.

[11] M. Goedkoop, M., Heijungs, R., Huijbregts, A. De schryver, J. Struijs, R. Van Zelm (2008): ReCiPe: a life cycle impact assessment method which comprises harmonised category indicators at the midpoint and the endpoint level. first edition (revised) 2008.

[12] F. Bottoli and L. Pignatti, Design and Processing of Structural Components in Biocomposite Materials - Case Study: Rotor Blades for Wind Turbine Cars. Risø, DK: Master Thesis, 2011. 
[13] Markussen C.M., Birkved M., Madsen, B. (2013): Quantitative sustainability assessment of conventional and bio-based composite material. A case study of a small-scale wind turbine blade. To be published.

[14] M. Ashby. Material selection in mechanical design. 4th edition.

[15] PE GaBi 4.4. Compilation 4.4.131.1. Stuttgart, Germany: PE International - SoftwareSystem and Databases for Life Cycle Engineering, 2011.

[16] PE, Professional Database version 4.131. Stuttgart, Germany: PE International - SoftwareSystem and Databases for Life Cycle Engineering, 2011.

[17] Swiss Centre for LCI, ecoinvent v. 2.2. St-Gallen, Switzerland: Swiss Centre for Life Cycle Inventories, 2011.

[18] R. Rusu, S.A.E Boyer, M-F Lacrampe, and P. Krawczak. Bioplastics and vegetal fibre reinforced bioplastics for automotive application. In Pilla S 2011. Handbook of bioplastics and biocomposites. Engineering applications. John Wiley and Sons Inc., USA, 2011.

[19] Entropy Resin. MSDS - Super Sap 100 Epoxy. Entropy Resins, California, USA, 2011a.

[20] EC-JRC (2010b) Framework and requirements for LCIA models and indicators. ILCD Handbook-International Reference Life Cycle Data System, European Union EUR24586EN. ISBN 978-92-79-17539.

[21] P. Stenius. Forest Products Chemistry, Papermaking Science and Technology. Vol. 3. Fapet Oy, Helsinki University of Technology, Finland, 2000.

[22] Entropy Resin. MSDS - Super Sap ONE Hardener. Entropy Resins, California, USA, 2011 b.

[23] Khubchandani R. (2011): flax fibre composites for small wind turbine blades. Master thesis Ris $\varnothing$ DTU, national laboratory for sustainable energy, Denmark.

[24] J. Beauson, C.M. Markussen, B. Madsen. Analysis of composition and microstructural uniformity of hybrid glass/carbon fibre composites, (2013) proceedings of the 34th Ris $\emptyset$ international symposium on materials science.

[25] Weidma and Wesnaes (1996): Data quality management for life cycle inventories - an example of using data quality indicators. J. Cleaner Prod. Vol 4 (3-4) pp. 167.17.

[26] Price, L. and Kendall, A. (2012), Wind Power as a Case Study. Journal of Industrial Ecology, 16: S22-S27. doi: 10.1111/j.1530-9290.2011.00458.x. 